\title{
Geoprocessing via Google Maps for Assessing Obesogenic Built Environments Related to Physical Activity and Chronic Noncommunicable Diseases: Validity and Reliability
}

\author{
Valter Silva $^{1 *}$, Antonio Jose Grande ${ }^{2}$, Cassiano Ricardo Rech ${ }^{3}$ and Maria Stella \\ Peccin $^{1}$ \\ ${ }^{1}$ Universidade Federal de São Paulo, SP, Brazil \\ ${ }^{2}$ Universidade do Extremo Sul Catarinense, SC, Brazil \\ ${ }^{3}$ Universidade Federal de Santa Catarina, SC, Brazil
}

Submitted October 2014. Accepted for publication November 2014.

\begin{abstract}
This study analyzes the reliability and validity of obesogenic built environments related to physical activity and chronic noncommunicable diseases through Google Maps in a heterogeneous urban area (i.e., residential and commercial, very poor and very rich) in São Paulo (SP), Brazil. There are no important differences when comparing virtual measures with street audit. Based on Kappa statistic, respectively for validity and reliability, $78 \%$ and $80 \%$ of outcomes were classified as nearly perfect agreement or substantial agreement. Virtual measures of geoprocessing via Google Maps provided high validity and reliability for assessing built environments.
\end{abstract}

Keywords: obesity, motor activity, environment and public health, chronic disease, geographic information systems

\section{INTRODUCTION}

According to data from the World Health Organization, chronic noncommunicable diseases are the leading cause of mortality worldwide for 36 million people per year or $63 \%$ of all deaths [1]. Among the leading causes, there are modifiable behavioral risk factors, such as sedentarism and obesity, which together cause $23 \%$ of premature deaths, or 8.1 million/year, worldwide from chronic noncommunicable diseases. These modifiable behavioral risk factors may influence most of the other causes [1].

There is a large body of evidence that supports the notion that lifestyle choices may be influenced by the characteristics of the environments in which individuals grow and live [2-8]. For example, the results of Hankey et al. [2] showed 7 fewer deaths/100,000/year in high- vs. low-walkability neighborhoods caused by ischemic heart disease.

Therefore, it is necessary for policymakers and researchers to understand aspects of built environments in order to plan and organize community strategies and public policy

*Corresponding author: Valter Silva, Universidade Federal de São Paulo, Rua Botucatu, 740 - 3 andar, Vila Clementino, São Paulo - SP, Brasil, CEP 04023-900. Phone: +55 11 5576-4203. E-mail: v.silva@ymail.com. Other authors: grandeto@gmail.com; crrech@hotmail.com; stella.peccin@gmail.com. 
Noncommunicable Diseases: Validity and Reliability

intervention related to the burden of diseases by obesity and sedentarism on a population level $[3,8,9]$. Recruiting and training people to assess the characteristics of built community environments is very expensive and time consuming. Considering that the current international scenario is recovering from global economic crisis, innovative and efficient interventions should be studied to maximize investments, maintain the quality of the measurements [9], and create opportunities for a country to avoid environments causing economic burden.

Tools such as Google Maps (which contains Google Street View, Google Earth, and Google Satellite) can monitor obesogenic environments with remarkable time, investment, and labor efficiency - these tools require only a computer with Internet access [9-13]. However, this method of environment assessment raises doubts about the validity and reliability of remote measurements when compared with street audit measurements [8,9,14-23]. Complex factors, such as Brazil's mixed residentialcommercial, rich-poor areas, bring a new and challenging perspective of the usefulness of Google Maps with assessing built environments in different settings. Thus, the objective of this study was to analyze the reliability and validity of the characteristics of the obesogenic built environment related to physical activity and chronic noncommunicable diseases through Google Maps.

\section{METHODS}

\subsection{Study Design, Sample, and Setting}

This analytical research was designed to determine the validity and reliability of the assessment of obesogenic built environments related to physical activity and chronic noncommunicable disease through geoprocessing via Google Maps. Google Maps was chosen because of its innovation with applications and simplicity in terms of usage, absence of costs, and easy access as it requires only a computer with an Internet connection. Additionally, Google Street View is being updated and expanded throughout the world (see Figure 1). The unit of analysis in this study was composed by

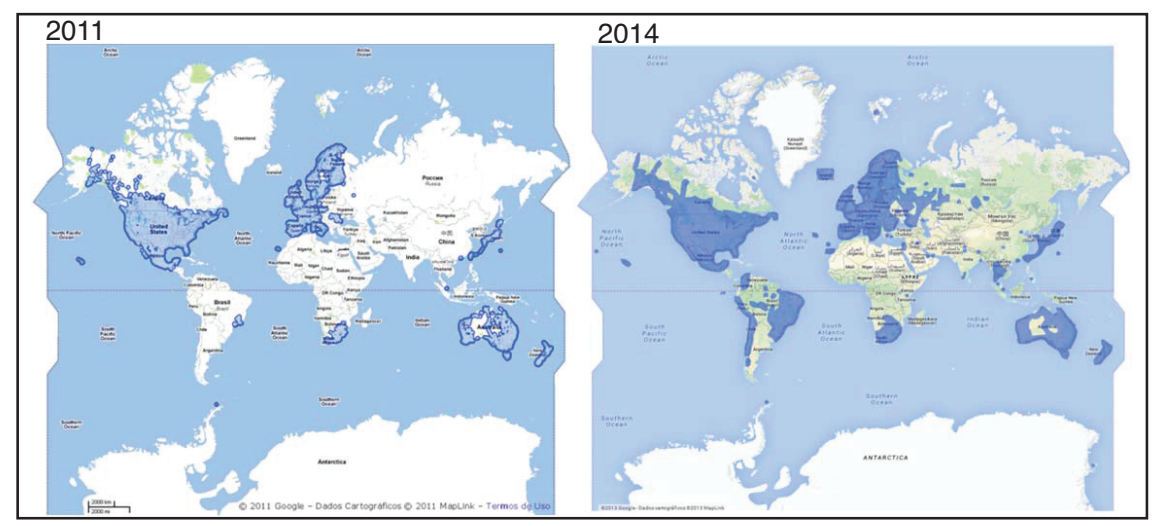

Figure 1. A comparison of global coverage of Google Street View maps between 2011 and 2014. 
a sample of 29 segments delimited by the geographic coordinate system (see http://goo.gl/algV8C: "eTable 1. Decimal degrees for latitude and longitude of each segments, Sta Catarina Avenue, São Paulo (SP), Brazil"). These 29 samples of the built environment were obtained from a main road, the Sta Catarina Avenue, within a heterogeneous urban area (see http://goo.gl/avOlqA: Figure S1. Most heterogeneous landscapes from the buffer of Sta Catarina Avenue) of the Jabaquara district, a southern region of the fourth largest city in the world, São Paulo (SP), Brazil. A segment considered in this study is defined as a section of roadway delimited by each crossing of each block on which the environment is built for vehicles traveling or a sidewalk where only people may travel.

According to information from the City Hall of São Paulo [24], in 2011, the Jabaquara district was the $13^{\text {th }}$ most populous district and included 34 slums. Within São Paulo, there were 223,780 inhabitants in an area of $14.1 \mathrm{~km}^{2}$ and the population density was 15.9 people per $\mathrm{km}^{2}$. The district's Human Development Index (HDI) of 0.858 was high in comparison to São Paulo City at 0.805 , São Paulo State at 0.783 , and Brazil at 0.728 .

Based on Google Maps' information, this avenue is $3.1 \mathrm{~km}$ long. It is composed of 29 segments with about 22,000 commercial establishments in its neighborhood. It is located next to important points of the city, such as São Paulo Airport/Congonhas (IATA: CGH) (3.5 km), Jabaquara Intermodal Terminal (integration among Metro station, municipal and intermunicipal buses) $(1.9 \mathrm{~km})$, Conceição Metro station (3.1 km), Fontes do Ipiranga State Park $(5.0 \mathrm{~km})$, Ibirapuera Park $(7.7 \mathrm{~km})$, Washington Luís Avenue $(0.0 \mathrm{~km})$, Imigrantes Highway $(3.2 \mathrm{~km})$, Marginal Pinheiros Avenue $(5.5 \mathrm{~km})$, and Bandeirantes Avenue $(3.0 \mathrm{~km})$. Essentially, the Sta Catarina Avenue was selected because of Google Street View coverage and the characteristics of places nearby. It is important to mention that in its extension, there are three HDI ranges (0.774 to $0.813,0.813$ to 0.858 , and 0.910 to 0.972 ) [24] (Figure 2, Part A) across six neighborhoods. Also, note that a dwelling may range between $\$ 22,000$ U.S. dollars and \$1.7 million U.S. dollars (based on data from FipeZap House Asking Price Index (FipeZap Index) from 2011 and corrected to dollars of 2014, a price index for residential property; see http://goo.gl/avOlqA: Figure S1. Most heterogeneous landscapes from the buffer of Sta Catarina Avenue). In addition, Part A of Figure 2 shows views of the buffer of Sta Catarina Avenue inside the Jabaquara district, inside São Paulo city, inside the metropolitan region of São Paulo, inside the São Paulo state, and all inside Brazil. The next four maps/views were provided by Google tools (Maps, Satellites, Earth, and Street View) and show Sta Catarina Avenue inside a buffer with a one-kilometer, which contains green spaces/squares and poor places for physical activity. A detailed map with the buffer of the evaluated region is available at http://goo.gl/maps/KMLi.

\subsection{Measurements}

\subsubsection{Outcomes}

The main outcome of this study was the obesogenic built environment related to physical activity and chronic noncommunicable diseases. This outcome was based 


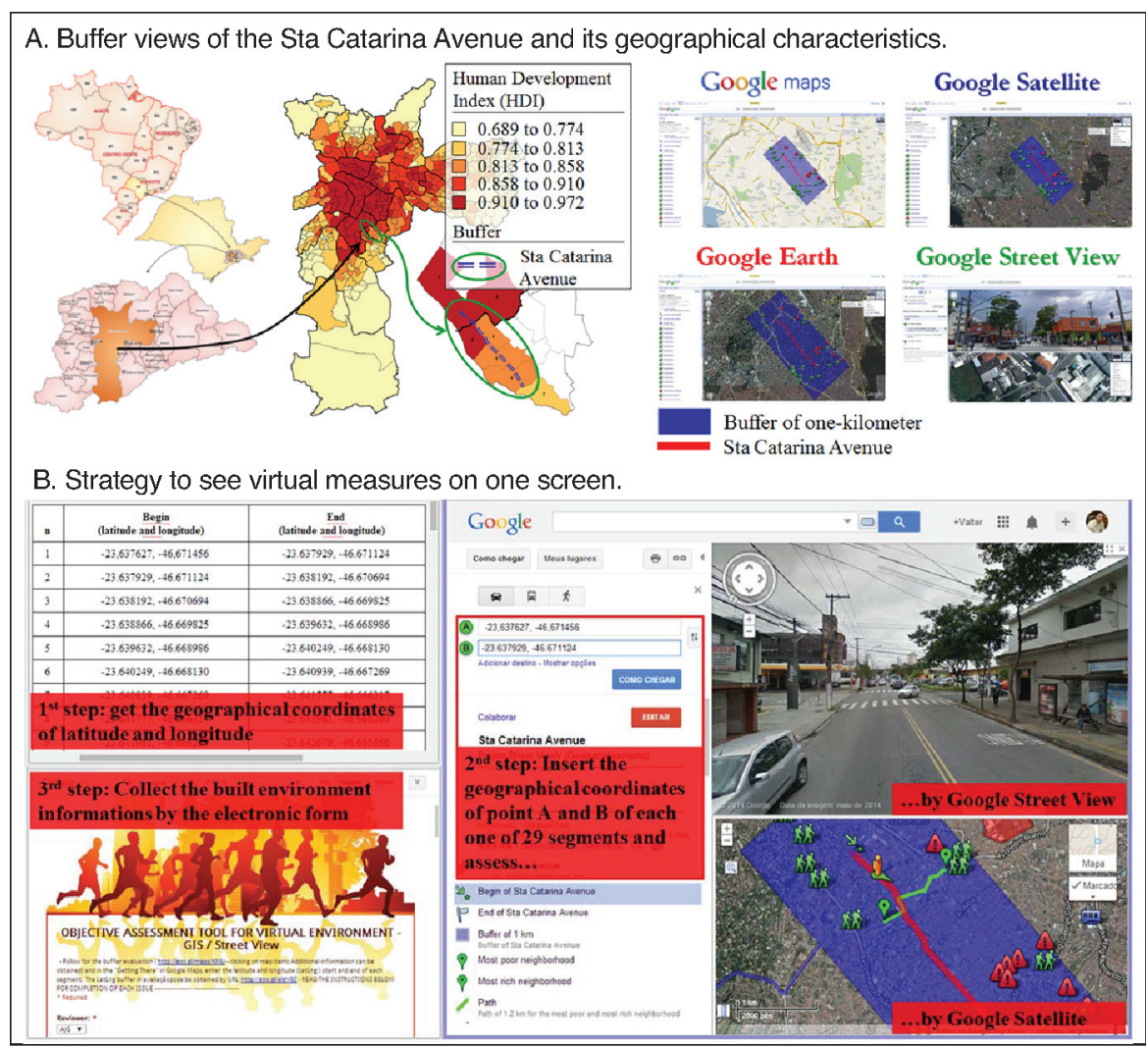

Figure 2. Characteristics of analyzed buffer (Part A) and strategy to see virtual measures on one screen (Part B).

on a validated tool [3] (agreement $>75 \%$ ) called Objective Evaluation of Environment. We consider that the obesogenic environment related to physical activity and chronic noncommunicable diseases are associated with the built environment around where people live or work. This environment may lead to weight gain and sedentarism or may create barriers to weight loss or inhibit physical activity, increasing the risk of chronic noncommunicable diseases. Thus, ten aspects were evaluated: 1) type of road structure (flooring); 2) type of cross street; 3) existence of sidewalks; 4) irregularities on sidewalks; 5) bus stops; 6) crosswalks; 7) traffic lights; 8) street lights; 9) slope of the land; 10) the presence of green spaces/squares (including public parks).

Each of the 29 segments of Sta Catarina Avenue was assessed by virtual and street audit measurement based in decimal degrees to express latitude $\left(90^{\circ} \mathrm{N}\right.$ or $\left.90^{\circ} \mathrm{S}\right)$ and longitude $\left(180^{\circ} \mathrm{E}\right.$ or $\left.180^{\circ} \mathrm{W}\right)$ of the geographic coordinate system (see 
http://goo.gl/algV8C: eTable 1. Decimal degrees for latitude and longitude of each segments, Sta Catarina Avenue, São Paulo (SP), Brazil).

\subsubsection{Virtual Measures by Google Maps}

Firstly, virtual measures were collected by four researchers (AJG, CRR, SAF, and VS) who had similar background experience with the software used (i.e., only daily use) and, additionally, had only four days to learn all tools. The four researchers carried out the assessment of the built environment and independently collected the geoprocessing information by Google Maps. Google Street View was used as the main tool because it uses real images to analyze locations accurately. It also uses panoramic views of $360^{\circ}$ horizontal and $290^{\circ}$ vertical scales and allows users to see with great detail regions of the world at the land level. Google Maps, Google Satellite, and Google Earth were used as support tools.

Each of the 29 segments of Sta Catarina Avenue was defined by geographical coordinates of latitude and longitude before data collection to standardize the areas assessed (see http://goo.gl/algV8C: eTable 1. Decimal degrees for latitude and longitude of each segments, Sta Catarina Avenue, São Paulo (SP), Brazil). An electronic form containing the assessment tool of the built environment and additional information was developed to standardize and facilitate the data collection, as shown in Part B of Figure 2 (see http://goo.gl/ZHCTE8: Assessment Instrument Virtual Environment Objective-GIS/Street View).

The Google Street View tools (supported by Google Maps, Google Satellite and Google Earth) were simultaneously arranged on the computer screen along with the document containing the geographic coordinates and an electronic form to collect the virtual measure (see Figure 2, Part B).

\subsubsection{Direct Observation by Street Audit Measure}

Researcher VS performed the second part of the study, street audit assessment, in the selected region seven days after collecting virtual measures, VS used a printed version of the form that was very similar to the electronic version and respected the same geographic coordinates. This assessment consisted of direct observation in all places, i.e., measures in loco, which is the gold standard.

\subsection{Statistical Analysis}

\subsubsection{Reliability}

Virtual measurements collected by four independent researchers were used to establish inter-rater reliability of geoprocessing measurements via Google Maps. The measures were analyzed by the percentage of agreement between observers and the PrevalenceAdjusted Bias-Adjusted Kappa (PABAK) [25], followed by a test of a sample for binomial proportions. The Friedman ANOVA (Fr) was used to compare the measurements obtained by the four researchers.

\subsubsection{Validity}

For the validity of geoprocessing via Google Maps, the street audit measures obtained by one researcher (VS) were compared with the virtual measures obtained by four 
Noncommunicable Diseases: Validity and Reliability

Table 1. Reliability of geoprocessing via Google Maps established by comparing* virtual measurements.

\begin{tabular}{|c|c|c|c|c|c|}
\hline \multirow[b]{2}{*}{ Built Environment } & \multicolumn{4}{|c|}{ Researchers } & \multirow[b]{2}{*}{$\mathbf{F r} \mathbf{d f}_{(\mathrm{f})} ; \mathbf{p}$} \\
\hline & AJG & CRR & SAF & VS & \\
\hline Flooring ${ }^{1}$ & $1.00 \pm 0.00$ & $1.00 \pm 0.00$ & $1.00 \pm 0.00$ & $1.00 \pm 0.00$ & $<0.01 ;>0.99$ \\
\hline Number of cross streets & $1.62 \pm 0.49$ & $1.90 \pm 0.62$ & $1.55 \pm 0.57$ & $1.69 \pm 0.54$ & $1.87 ; 0.60$ \\
\hline Existence of sidewalk ${ }^{2}$ & $2.00 \pm 0.00$ & $2.00 \pm 0.00$ & $1.97 \pm 0.42$ & $2.00 \pm 0.00$ & $0.06 ;>0.99$ \\
\hline \multicolumn{6}{|l|}{ Number of irregularities } \\
\hline on sidewalks & $0.10 \pm 0.41$ & $0.59 \pm 1.18$ & $0.17 \pm 0.60$ & $0.21 \pm 0.62$ & $1.28 ; 0.73$ \\
\hline Number of bus stops & $0.76 \pm 0.64$ & $0.52 \pm 0.58$ & $0.59 \pm 0.63$ & $0.59 \pm 0.57$ & $1.45 ; 0.69$ \\
\hline Number of crosswalks & $1.45 \pm 0.74$ & $1.62 \pm 0.62$ & $1.41 \pm 0.91$ & $1.69 \pm 0.54$ & $3.07 ; 0.38$ \\
\hline Number of traffic lights & $0.90 \pm 0.82$ & $0.93 \pm 0.84$ & $0.86 \pm 1.03$ & $0.93 \pm 0.80$ & $0.22 ; 0.98$ \\
\hline Number of streetlights & $2.90 \pm 1.18$ & $2.24 \pm 0.99$ & $3.10 \pm 1.47$ & $3.10 \pm 1.26^{\mathrm{b}}$ & $10.11 ; 0.03$ \\
\hline Slope of the land ${ }^{3}$ & $1.38 \pm 0.49$ & $1.14 \pm 0.35$ & $1.21 \pm 0.41$ & $1.10 \pm 0.31$ & $3.15 ; 0.37$ \\
\hline Number of green spaces/squares & $0.00 \pm 0.00$ & $0.00 \pm 0.00$ & $0.00 \pm 0.00$ & $0.00 \pm 0.00$ & $<0.01 ;>0.99$ \\
\hline
\end{tabular}

*Descriptive values of mean \pm standard deviation; ${ }^{b}$ Significant difference from CRR; ${ }^{1}$ Flooring $(1=$ asphalt; $2=$ dirt $) ;{ }^{2}$ Existence of sidewalks $(0=$ none; $1=$ only on one side; $2=$ on both sides $) ;{ }^{3}$ Type of slope of the land $(1=$ even/level; 2 = uphill/downhill $) ;$ Fr = Friedman ANOVA.

researchers (AJG, CRR, SAF and VS). We used the percentage agreement and PABAK, followed by a test of a sample for binomial proportions. The Fr was used to compare the virtual and direct measurements.

\subsubsection{Interpretation}

For validity and reliability of the observed measurements' agreement, the method of [26] was employed: Absence of agreement $(=0.0)$; Slight agreement $(\geq 0.0$ and $\leq 0.2)$; Fair agreement $(>0.2$ and $\leq 0.4)$; Moderate agreement $(>0.4$ and $\leq 0.6)$; Substantial agreement $(>0.6$ and $\leq 0.8)$; and Nearly perfect agreement $(>0.8)$. The statistical summary of the data is presented as mean, standard deviation (sd), absolute frequencies, relative frequencies, and a confidence interval (CI) of $95 \%$ calculated by the Wilson score (recommended by [27] for small sample size, i.e., $n \leq 40$ ). The significance level for all analyses was $\mathrm{p}<0.05$.

\section{RESULTS}

\subsection{Characteristics of the Study}

The mean extension of the segments was 103.2 (sd 34.5) meters and the time of evaluation varied between 4:37 to 7:11 minutes in street audits and 4:11 to 8:38 minutes via Google Maps. In its extension, there are three HDI ranges $(0.774$ to $0.813,0.813$ to 0.858 , and 0.910 to 0.972 ) and the cost of a home may range between $\$ 22,000$ U.S. dollars and \$1.7 million U.S. dollars (see http://goo.gl/avOlqA: Figure S1. Most heterogeneous landscapes from the buffer of Sta Catarina Avenue). Geomorphology 


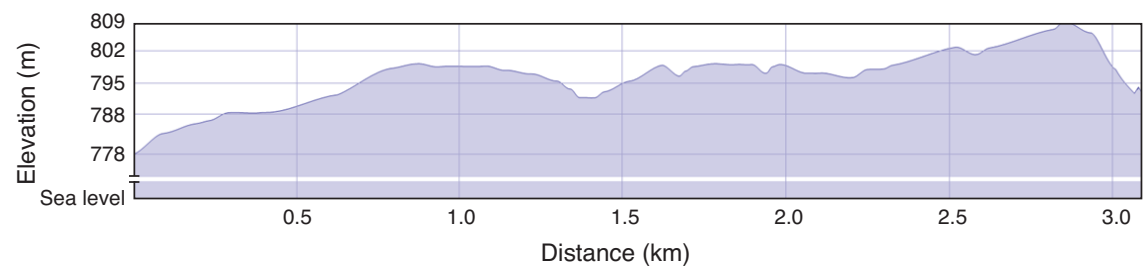

The $\mathrm{x}$-axis presents the distance along the Sta Catarina Avenue $(3.1 \mathrm{~km})$; the $y$-axis presents the elevation profile above the sea level-average/minimum/maximum elevation: $796 \mathrm{~m}, 782 \mathrm{~m}, 811 \mathrm{~m}$; elevation gain/loss: 51.7 m, 37.3 m; maximum slope: $8.8 \%,-12.2 \%$; average slope: $2.7 \%,-2.9 \%$.

Figure 3. Geomorphology characteristics of the Sta Catarina Avenue.

characteristics of the Sta Catarina Avenue are represented by distance and elevation profile (average/minimum/maximum elevation, elevation gain/loss, maximal slope and average slope) (Figure 3). The elevation gain represents the positive change in altitude between the start of a hike and its high point. Elevation loss is just the opposite of elevation gain, representing the negative change in altitude when descending a route. The slopes represents rates of changes in elevation between two points in a given area. These factors are used in assigning difficulty ratings.

Based on street audit measurements, the region had the following characteristics: asphalt flooring; approximately two cross streets per segment; pavement on both sides of the sidewalks; irregularities on the sidewalks every four segments; approximately one bus stop every two segments; approximately two crosswalks per segment; one traffic light per segment; three streetlights per segment; in every 14 segments, one considered uphill/downhill. Additionally, there were no green spaces/square areas (including public parks) connected directly to the area assessed; however, within one kilometer from the evaluated buffer region, there were green spaces/squares viable for physical activity (see map of street view at http://goo.gl/maps/KMLi).

\subsection{Reliability}

Except for the number of streetlights $(\mathrm{p}=0.03)$, there were no statistically significant differences observed among geoprocessing measurements using Google Maps collected independently by the four researchers. There is a difference in the number of streetlights between two researchers (VS and CRR), and there were no significant differences for the other characteristics (see Table 1).

The agreements among the four researchers for virtual measurements ranged between $72 \%$ and $100 \%$, and all values of percent agreement were statistically different from the absence of agreement $(\mathrm{p}<0.05)$. Based on the kappa statistic, the agreement was classified as nearly perfect $(>0.8$ ) for the flooring, existence of sidewalks, and green spaces/squares; the agreement was classified as substantial $(>0.6$ and $\leq 0.8)$ for the number of cross streets, sidewalks irregularities, crosswalks, traffic lights, and slope of the land; the agreement was classified as moderate $(>0.4$ and $\leq 0.6)$ for the bus stops; and only the streetlights were classified as fair agreement $(>0.2$ and $\leq 0.4)$ (see Table 2 ). 
Table 2. Reliability of geoprocessing via Google Maps established by inter-rater measurements agreement.

\begin{tabular}{|c|c|c|}
\hline \multirow[b]{2}{*}{ Built Environment } & \multicolumn{2}{|c|}{ Agreement ${ }^{\#}$} \\
\hline & Kappa $^{\mathbb{I}}(95 \%$ CI $)$ & $\%(95 \%$ CI $) ;$ hits $^{¥}$ \\
\hline Flooring $^{1}$ & $1.00(0.83,1.00)$ & $100(88.3,100) ; 29$ \\
\hline Cross streets & $0.66(0.49,0.84)$ & $82.8(65.5,92.4) ; 24$ \\
\hline Existence of sidewalk ${ }^{2}$ & $0.97(0.80,1.00)$ & $96.6(82.8,99.4) ; 28$ \\
\hline Irregularities on sidewalks & $0.78(0.61,0.96)$ & $86.2(69.4,94.5) ; 25$ \\
\hline Bus stops & $0.55(0.38,0.72)$ & $82.8(65.5,92.4) ; 24$ \\
\hline Crosswalks & $0.65(0.49,0.80)$ & $75.9(57.9,87.8) ; 22$ \\
\hline Traffic lights & $0.63(0.47,0.79)$ & $86.2(69.4,94.5) ; 25$ \\
\hline Streetlights & $0.27(0.14,0.39)$ & $72.4(54.3,85.3) ; 21$ \\
\hline Slope of the land ${ }^{3}$ & $0.71(0.54,0.88)$ & $82.8(65.5,92.4) ; 24$ \\
\hline Green spaces/squares & $1.00(0.83,1.00)$ & $100(88.3,100) ; 29$ \\
\hline
\end{tabular}

${ }^{\#}$ All agreements were statistically significant $(\mathrm{p}<0.05)$; IPrevalence-Adjusted Bias-Adjusted Kappa (PABAK); ${ }^{\ddagger}$ The absolute value of agreement among all researchers; ${ }^{1}$ Flooring $(1=$ asphalt; 2 = dirt $)$; ${ }^{2}$ Existence of sidewalks $\left(0=\right.$ none; $1=$ only on one side; $2=$ on both sides); ${ }^{3}$ Type of slope of the land ( 1 = even/level; 2 = uphill/downhill).

\subsection{Validity}

When a researcher (VS) compared the street audit measurements twice with geoprocessing measurements by Google Maps, with one-week period between the two assessments, no statistically significant differences were observed for all aspects of the built environment (see Table 3).

Agreement between geoprocessing measures by Google Maps with street audit measurements are presented in Table 4. The percent agreement varied from 38\% to $100 \%$, and the Kappa statistic ranged between 1.00 and 0.07. Except for the Kappa of the streetlights by the researcher CRR, all values were statistically different than zero (absence of agreement; $\mathrm{p}<0.05$ ). From interpreting Kappa statistics based on the 10 built environment characteristics measured in this study, we obtained the following results of validity from each researcher: the researcher AJG obtained 5/10 measures with nearly perfect agreement $(>0.8), 3 / 10$ measures with substantial agreement $(>0.6$ and $\leq 0.8), 1 / 10$ measures with moderate agreement $(>0.4$ and $\leq 0.6)$, and $1 / 10$ measures with fair agreement $(>0.2$ and $\leq 0.4)$; the researcher CRR obtained $4 / 10$ measures with nearly perfect agreement $(>0.8), 2 / 10$ measures with substantial agreement $(>0.6$ and $\leq 0.8), 2 / 10$ measures with moderate agreement $(>0.4$ and $\leq 0.6), 1 / 10$ with fair agreement $(>0.2$ and $\leq 0.4)$, and $1 / 10$ with slight agreement $(>0.0$ and $\leq 0.2)$; researcher SAF obtained $7 / 10$ measures with nearly perfect agreement $(>0.8), 1 / 10$ measures with substantial agreement $(>0.6$ and $\leq 0.8)$, and $2 / 10$ with fair agreement $(>0.2$ and $\leq 0.4)$; the researcher VS obtained $8 / 10$ measures with near perfect agreement $(>0.8), 1 / 10$ measure with substantial agreement $(>0.6$ and $\leq 0.8)$, and $1 / 10$ with moderate agreement 
Table 3. Validity of geoprocessing via Google Maps established by comparing* street audit with the virtual measurements.

\begin{tabular}{lccc}
\hline Built environment & Street audit & Virtual & $\mathbf{F r}_{(\mathbf{d f}=1)} ; \mathbf{p}$ \\
\hline Flooring ${ }^{1}$ & $1.00 \pm 0.00$ & $1.00 \pm 0.00$ & $<0.01 ;>0.99$ \\
Number of cross streets $^{\text {Existence of sidewalk }}{ }^{2}$ & $1.76 \pm 0.57$ & $1.69 \pm 0.54$ & $0.04 ; 0.85$ \\
Number of irregularities on sidewalks & $0.24 \pm 0.69$ & $0.21 \pm 0.62$ & $<0.01 ;>0.99$ \\
Number of bus stops & $0.66 \pm 0.55$ & $0.59 \pm 0.57$ & $0.14 ; 0.71$ \\
Number of crosswalks & $1.66 \pm 0.48$ & $1.69 \pm 0.54$ & $0.03 ; 0.85$ \\
Number of traffic lights & $0.86 \pm 0.83$ & $0.93 \pm 0.80$ & $0.14 ; 0.71$ \\
Number of streetlights & $2.97 \pm 1.05$ & $3.10 \pm 1.26$ & $0.55 ; 0.46$ \\
Slope of the land & $1.14 \pm 0.35$ & $1.10 \pm 0.31$ & $0.04 ; 0.85$ \\
Number of green spaces/squares & $0.00 \pm 0.00$ & $0.00 \pm 0.00$ & $<0.01 ;>0.99$ \\
\hline
\end{tabular}

*Descriptive values of mean \pm standard deviation; ${ }^{1}$ Flooring $(1=$ asphalt; $2=$ dirt $) ;{ }^{2}$ Existence of sidewalks $(0=$ none; $1=$ only on one side; $2=$ on both sides $) ;{ }^{3}$ Type of slope of the land $(1=$ even/level; $2=$ uphill/downhill); Fr = Friedman ANOVA.

( $>0.4$ and $\leq 0.6$ ). Combining values of the researchers, more than three quarters $(78 \%)$ of the characteristics of the built environment were classified with substantial agreement $(>0.6$ and $\leq 0.8)$ or excellent $(>0.8)$.

\section{DISCUSSION}

In this study, we consider that the obesogenic environment related to physical activity and chronic noncommunicable diseases is associated with the built environment where people live or work. This environment may lead to weight gain and sedentarism or may create barriers to weight loss or physically activity and may increase the risk of chronic noncommunicable diseases. For example, if a grocery store is within 500 meters, people may access it by walking. Conversely, if there are potholes or irregularities on sidewalks, or if there are no crosswalks or traffic lights, then the built environment is obesogenic and can increase the risk of chronic noncommunicable diseases.

This is one of the pioneering studies that assesses the validity and reliability of geoprocessing via Google Maps. Nevertheless, this study stands out among others in terms of the following: (1) it was conducted in a heterogeneous environment; (2) it is uniquely carried out outside of a high-income country; (3) it uniquely applied the PABAK, a more sophisticated statistical method of computing the Kappa, i.e., adjusting the prevalence and bias. In addition, the importance of this research is twofold:

1) Several studies have demonstrated the association between lifestyle and health risk to the built environment and suggesting the relationship between obesogenic built environments and physical activity $[2,8,27]$. Street audit is used as the golden standard for these types of measurements; however, it requires 48-72 hours of prior training to collect information and observe the location, taking 


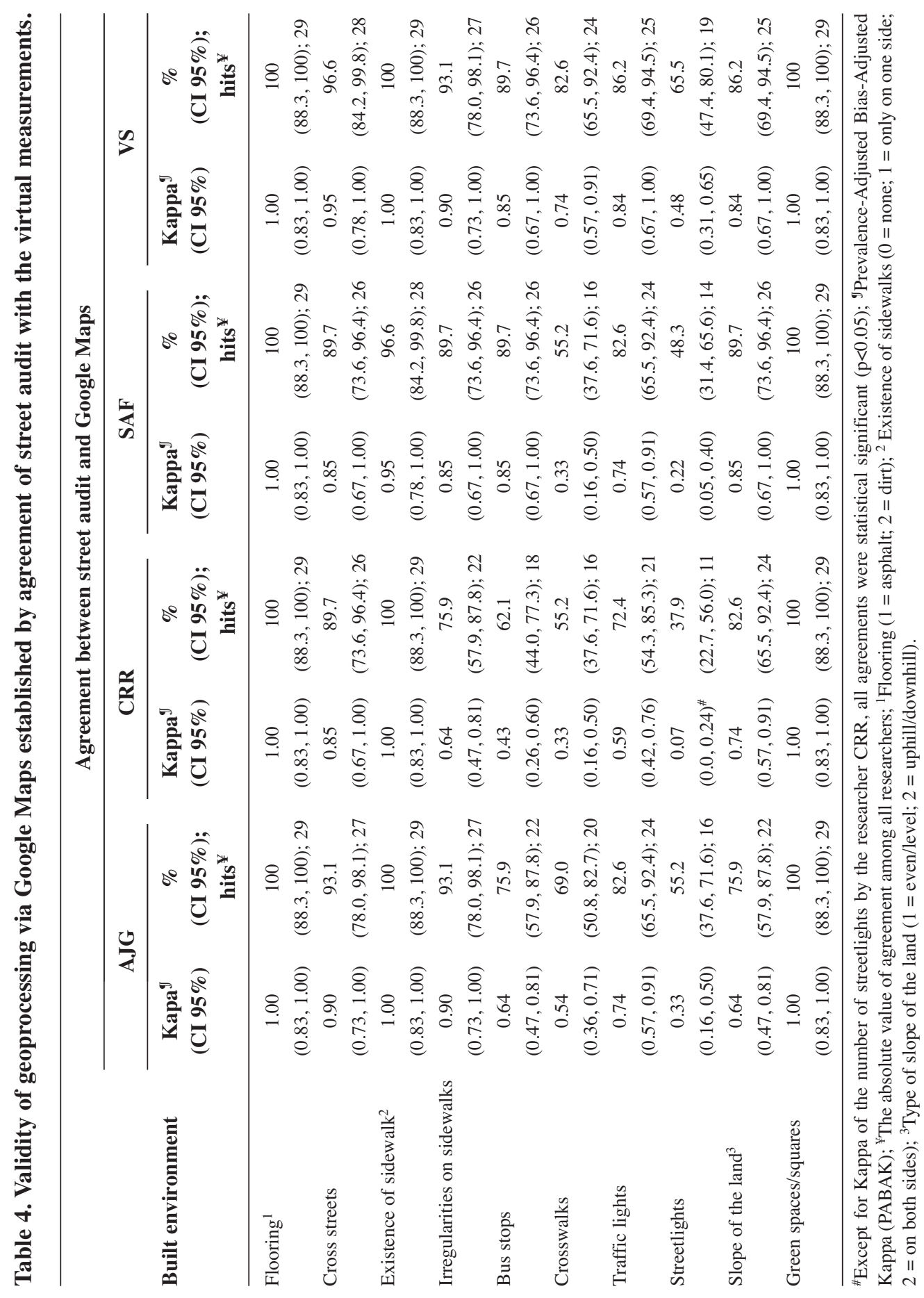


approximately 10 to 20 minutes per block [3,9]. For these reasons, this method is not easily applied in large areas and is only feasible for assessing neighborhoods or smaller communities.

2) Other studies have shown that a valid alternative to the measures implemented in the street audit are measurements obtained from geographic information systems $[2,5,20]$. This type of system solves part of the problems mentioned above; however, there is still the need to acquire software licenses and specialized training. Also, it is not possible to analyze the quality of the setting and built environment [9].

Therefore, it is critical to establish the validity and reliability of a geoprocessing tool like Google Maps. These types of tools have the following advantages: a) it can be used with little training; b) it enables the evaluation of cities around the world from a free platform that is easy to use; c) it enables the analysis of distances and routes; d) it enables map creation; e) it allows panoramic views of $360^{\circ}$ in horizontal and $290^{\circ}$ in vertical directions that can analyze the location accurately through the actual images at the ground level with great detail; and f) it requires only a computer with Internet.

Based on the information that could be obtained with geoprocessing tools, Google Maps has content validity as it covers different aspects of its objects. Additionally, this study has shown that the acquisition of information by Google Maps is reliable and valid for the assessment of obesogenic built environments for physical activity. Special attention should be given to the protocol of measurements, such as measurement of the number of streetlights, which has lower reliability and validity.

Considering our sample size (perhaps the main limitation of this study), we did not plan or perform post hoc subgroup analysis to understand the quality of information with regard to different characteristics, e.g., levels of HDI. However, we included a heterogeneous urban area (residential and commercial, very poor and very rich) in our study, that helped to understand the usability of Google Maps together with other studies [8] that were conducted in high-income countries with good walkability.

As shown by other studies [8,19-21], Google Maps requires less time to evaluate and compare street audit measurements with high reliability and validity in relation to the factors chosen to compose the instrument (i.e., public places for physical activity, safety, pattern of streets, existence and quality of sidewalks, aesthetics/cleanness, and public transportation) [8,27]. A systematic review [8] involving 13 studies published between 2010 and 2013 aimed to investigate the use of free geospatial services to assess environmental characteristics potentially associated with obesogenic built environments. The authors found that most of the 13 included studies were conducted in urban settings of North America. Another important point of this review is that the virtual instruments varied considerably from one study to another, and there was heterogeneity in the environmental items assessed.

Considering the constant changes of street and urban areas of built environments, the virtual images may become outdated and it may influence different measures; therefore, this is a possible limitation of this study and the virtual tool. Since developing countries are continuously changing, Google Street View may become outdated in certain regions in a shorter time compared to developed countries. Another limitation of this study is 
that we did not take into account the number of commercial destinations, the aesthetics of houses and neighborhoods, and some safety aspects. First, if food availability is high, it may influence the behavior of citizens to increase calorie intake, which could be associated with an obesogenic environment. Second, the presence of trash/garbage on sidewalks and streets, and abandoned houses, buildings, and cars are related to aesthetic factors; these could negatively influence the interest of physical activity. Third, traffic and violence are problems of big cities and could discourage physical activities. As a limitation of the tool, rural areas and poor neighborhoods are not well explored.

In using Google Maps to evaluate cities around the world, future studies should associate the obesogenic built environments related to physical activity with the leading causes of morbimortality worldwide attributed to noncommunicable diseases as well as factors from the community residents, such as sociodemographics, level of physical activity, measures of obesity, and possibly objective measures of each person in the community.

Planning the built environment can lead to positive health outcomes in a social network and will help city leaders create a healthy environment that can positively impact public policies at a population level $[28,30]$. It must be a continuous movement because humans change behavior over time. Thus, healthy places need to provide opportunities in the built and social environments for citizens to be physically active. Combined with the control of obesogenic factors, people will have more opportunities to have a better quality of life along with reduced risk of chronic noncommunicable diseases.

\section{CONCLUSION}

This study demonstrates that virtual measures based on Google Maps are reliable and valid for the assessment of obesogenic built environments that are related to outcomes of physical activity and health. The results of this study will help researchers and policymakers better address the issue of chronic noncommunicable diseases related to obesogenic built environment and physical activity at the population level.

\section{ACKNOWLEDGEMENT}

VS and AJG are grateful to CAPES (Coordination for the Improvement of Higher Education Personnel) for awarding their scholarships. We thank Silvio Aparecido Fonseca (SAF; Universidade Estadual de Santa Cruz, BA, Brazil) for his contribution to the study design, protocol development, data collection, interpretations of findings, and his comments on an earlier version of this paper.

\section{CONFLICT OF INTEREST}

The authors indicated no potential conflicts of interest.

\section{REFERENCES}

[1] World Health Organization. Global health risks: mortality and burden of disease attributable to selected major risks. Geneva: World Health Organization; 2009. http://www.who.int/healthinfo/global_burden_disease/GlobalHealthRisks_report_full.pdf. Accessed July 4, 2014. 
[2] Hankey S, Marshall JD, Brauer M. Health impacts of the built environment: within-urban variability in physical inactivity, air pollution, and ischemic heart disease mortality. Environ Health Perspect. 2012, 120(2):247-53.

[3] Bortoni WL, Florindo AA, Salvador EP, Reis RDS. Desenvolvimento e reprodutibilidade de um instrumento de avaliação objetiva do ambiente para aplicação em estudos de atividade física. Rev Bras Ativ Fís Saúde. 2009, 14(1):38-47.

[4] Tully MA, Kee F, Foster C, Cardwell CR, Weightman AL, Cupples ME. Built environment interventions for increasing physical activity in adults and children (Protocol). Cochrane Database Syst Rev. 2013, 1:CD010330.

[5] Yang L, Sahlqvist S, McMinn A, Griffin SJ, Ogilvie D. Interventions to promote cycling: systematic review. BMJ. 2010, 341:c5293.

[6] Feng J, Glass TA, Curriero FC, Stewart WF, Schwartz BS. The built environment and obesity: a systematic review of the epidemiologic evidence. Health Place. 2010, 16(2):175-90.

[7] Porter DE, Kirtland KA, Neet MJ, Williams JE, Ainsworth BE. Considerations for using a geographic information system to assess environmental supports for physical activity. Prev Chronic Dis. 2004, 1(4):A20.

[8] Charreire H, Mackenbach JD, Ouasti M, Lakerveld J, Compernolle S, Ben-Rebah M, McKee M, Brug J, Rutter H, Oppert JM. Using remote sensing to define environmental characteristics related to physical activity and dietary behaviours: a systematic review (the SPOTLIGHT project). Health Place. 2014, 25:1-9.

[9] Silva V. Avaliação objetiva do ambiente - uma proposta promissora. Rev Bras Ativ Fís Saúde. 2010, 15(3):195-196.

[10] Wilson JS, Kelly CM, Schootman M, Baker EA, Banerjee A, Clennin M, Miller DK. Assessing the built environment using omnidirectional imagery. Am J Prev Med. 2012, 42(2):193-9.

[11] Taylor BT, Fernando P, Bauman AE, Williamson A, Craig JC, Redman S. Measuring the quality of public open space using Google Earth. Am J Prev Med. 2011, 40(2):105-12.

[12] Bowman MA, Lupo P, Neale AV. Introduction of more editorial board members and google maps and google earth: the physician's cheap Geographic Information System (GIS). J Am Board Fam Med. 2010, 23(1):4-5.

[13] Boulos MNK. Web GIS in practice III: Creating a simple interactive map of England's Strategic Health Authorities using Google Maps API, Google Earth KML, and MSN Virtual Earth Map Control. Int J Health Geogr. 2005, 4:22.

[14] Lefer TB, Anderson MR, Fornari A, Lambert A, Fletcher J, Baquero M. Using google earth as an innovative tool for community mapping. Public Health Rep. 2008, 123(4):474-80.

[15] Wieczorek WF, Delmerico AM. Geographic Information Systems. Comput Stat. 2009, 1(2):167-186.

[16] Kono N, Arakawa K, Ogawa R, Kido N, Oshita K, Ikegami K, Tamaki S, Tomita M. Pathway projector: Web-based zoomable pathway browser using KEGG Atlas and Google Maps API. PLoS One. 2009, 4(11):e7710.

[17] Evenson KR, Sotres-Alvarez D, Herring AH, Messer L, Laraia BA, Rodriguez DA. Assessing urban and rural neighborhood characteristics using audit and GIS data: derivation and reliability of constructs. Int J Behav Nutr Phys Act. 2009, 6:44.

[18] Chang AY, Parrales ME, Jimenez J, Sobieszczyk ME, Hammer SM, Copenhaver DJ, Kulkarni RP. Combining Google Earth and GIS mapping technologies in a dengue surveillance system for developing countries. Int J Health Geogr. 2009, 8:49.

[19] Kelly CM, Wilson JS, Baker EA, Miller DK, Schootman M. Using Google Street View to audit the built environment: Inter-rater reliability results. Ann Behav Med. 2013, 45 Suppl 1:S108-12.

[20] Rundle AG, Bader MDM, Richards CA, Neckerman KM, Teitler JO. Using google street view to audit neighborhood environments. Am J Prev Med. 2011, 40(1):94-100

[21] Clarke P, Ailshire J, Melendez R, Bader M, Morenoff J. Using Google Earth to conduct a neighborhood audit: Reliability of a virtual audit instrument. Health Place. 2010, 16(6):1224-9 
[22] Badland HM, Opit S, Witten K, Kearns RA, Mavoa S. Can virtual streetscape audits reliably replace physical streetscape audits? J Urban Health. 2010, 87(6):1007-16

[23] Boone JE, Gordon-Larsen P, Stewart JD, Popkin BM. Validation of a GIS Facilities Database: Quantification and Implications of Error. Ann Epidemiol. 2008, 18(5):371-7.

[24] Subprefeitura Jabaquara. Secretaria Municipal de Coordenação das Subprefeituras. Prefeitura do Município de São Paulo. http://jabaquara.prefeitura.sp.gov.br/. Accessed December 28, 2013.

[25] Byrt T, Bishop J, Carlin JB. Bias, prevalence and kappa. J Clin Epidemiol. 1993, 46(5):423-429.

[26] Landis JR, Koch GG. The measurement of observer agreement for categorical data. Biometrics. 1977, 33:159-174.

[27] Brown LD, Cai TT, DasGupta A. Interval Estimation for a binomial proportion. Statist Sci. 2001, 16 (2):101-133.

[28] Rech CR, Reis RS, Hino AA, Hallal PC. Personal, social and environmental correlates of physical activity in adults from Curitiba, Brazil. Prev Med. 2013, 58:53-57.

[29] Sangachin MG, Samadi M, Cavuoto LA. Modeling the Spread of an Obesity Intervention through a Social Network. J Healthc Eng. 2014, 5(3):293-312.

[30] Edwards P, Tsouros AD. A healthy city is an active city: a physical activity planning guide. World Health Organization, Regional Office for Europe; 2008. 


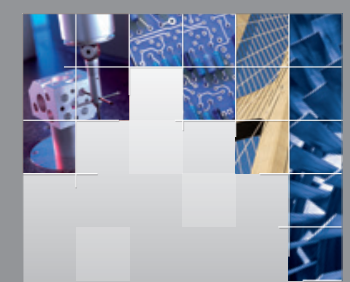

\section{Enfincering}
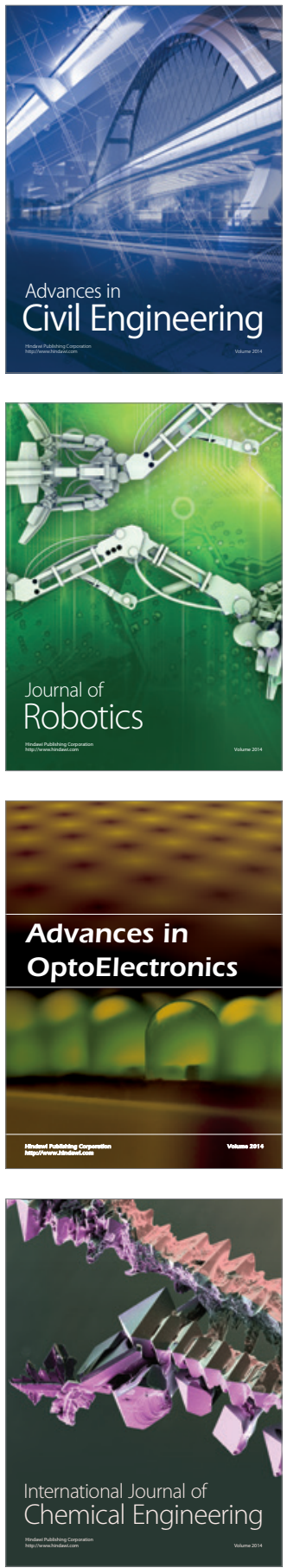

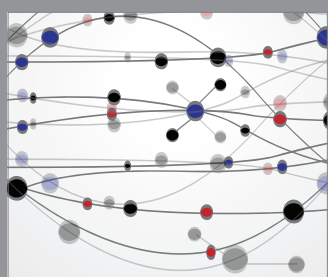

The Scientific World Journal

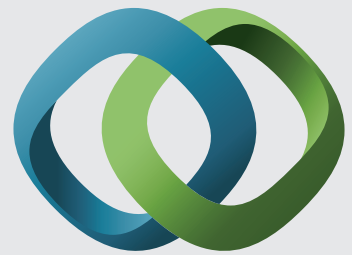

\section{Hindawi}

Submit your manuscripts at

http://www.hindawi.com
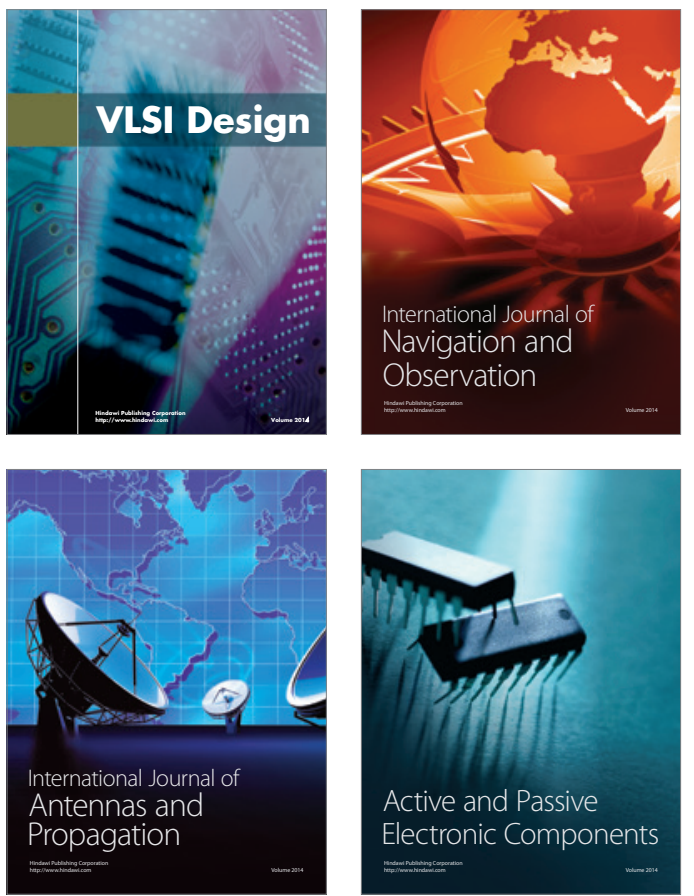
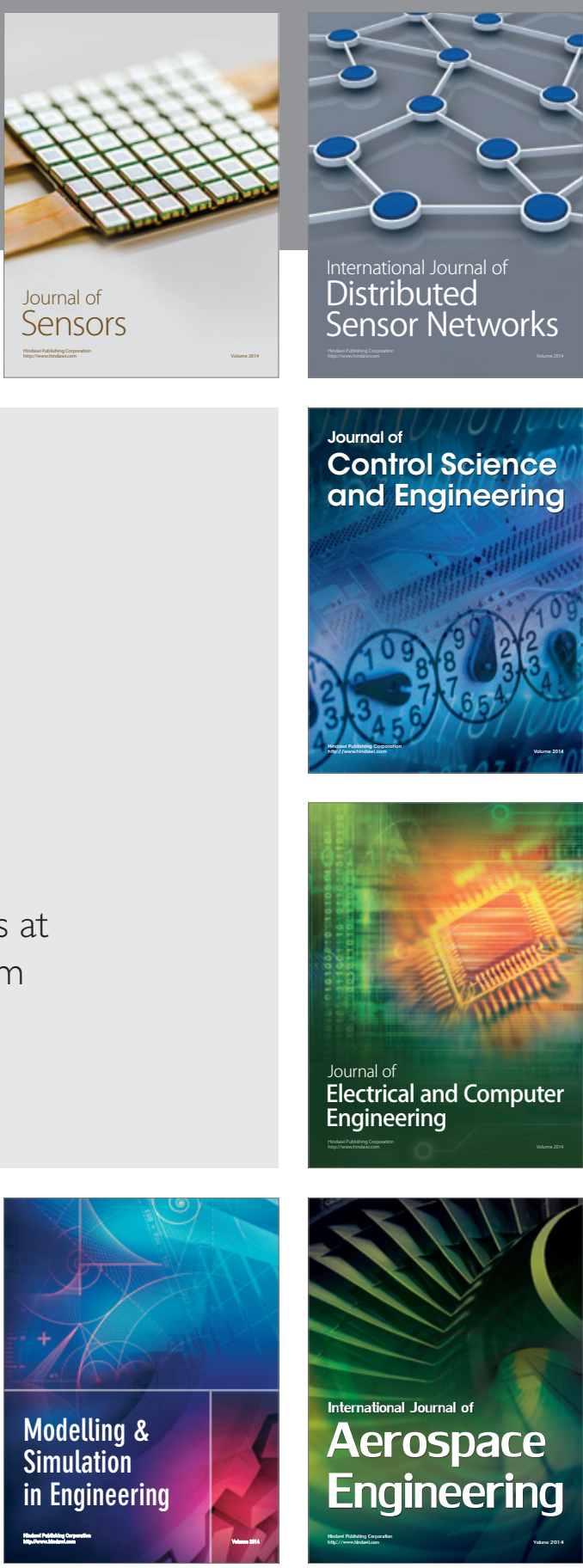

International Journal of

Distributed

Sensor Networks

Journal of

Control Science

and Engineering
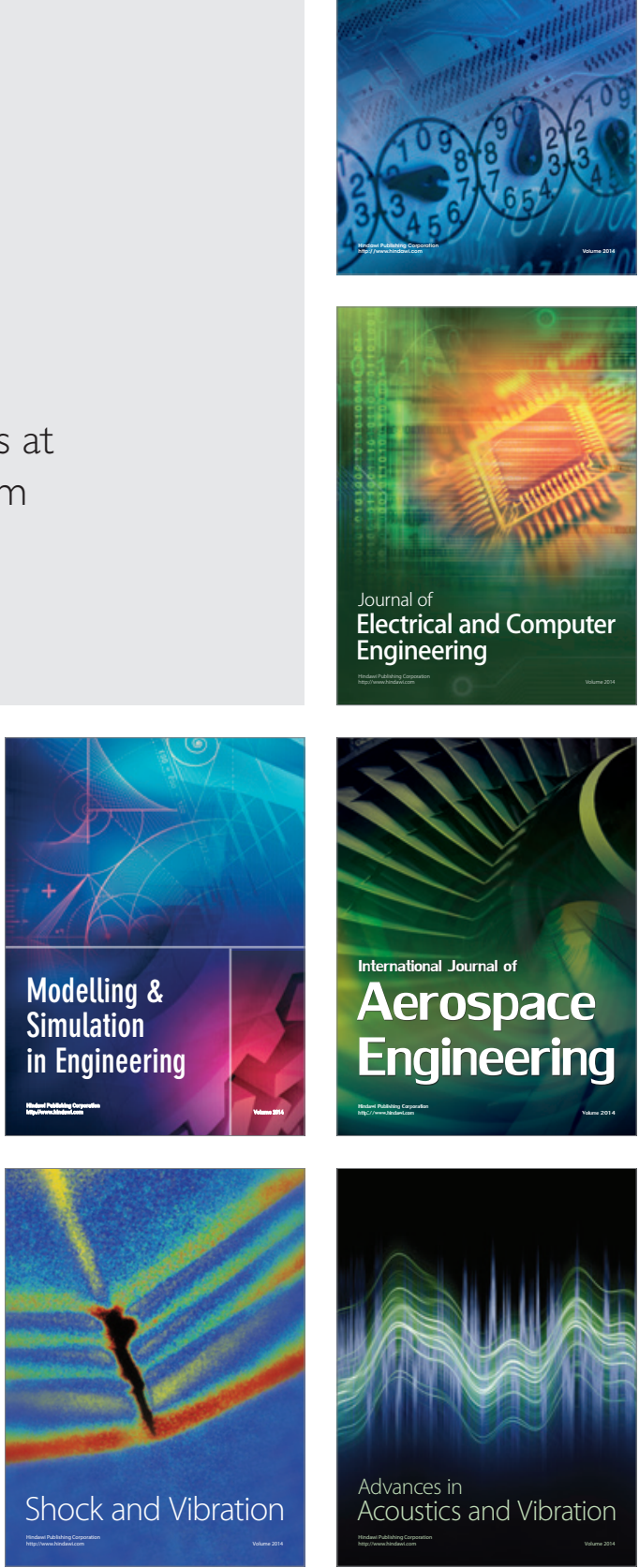